Conclusion Chromosomal microarray is useful prenatally particularly for an abnormal fetal USS. Prospective counselling should include the approximate VOUS rate $(1.4 \%$ rising to $2.1 \%$ for abnormal USS). It is likely that microarray testing will replace karyotyping in high risk pregnancies (such as abnormal USS).

\section{PF.02 THE ROLE OF QUANTITATIVE FETAL FIBRONECTIN AND CERVICAL LENGTH IN PREDICTING SPONTANEOUS PRETERM BIRTH IN MULTIPLE PREGNANCIES}

doi:10.1136/archdischild-2013-303966.014

R Mapara, DS Abbott, NL Hezelgrave, AH Shennan. Division of Women's Health, KCL, Women's Health Academic Centre, KHP, London, UK

Background Multiple pregnancies are associated with a higher risk of spontaneous preterm birth (sPTB). Whilst fetal fibronectin (fFN) and cervical length (CL) measurement can predict sPTB in singleton pregnancies (Kurtzman et al, 2009), their value for twin pregnancies is unknown.

Methods Prospective blinded secondary analysis of longitudinal samples of cervicovaginal fluid fFN concentration (nanograms per mililiter) using a bedside 10 qfFN analyzer (HOLOGIC, USA), and transvaginal ultrasound CL of 93 consecutive women with multiple pregnancies attending a Preterm Surveillance Clinic at St. Thomas Hospital from 18 weeks gestation (Oct 2010-Jan 2012). qfFN was assigned 4 ranges; $<10,10-50,50-200,>200(\mathrm{ng} / \mathrm{ml})$ to detect spontaneous delivery before 30,34 and 37 weeks. qfFN was blinded to clinicians using an embedded code in the analyzer.

Results The rate of sPTB ( $<37$ weeks) rose increased with increasing qfFN from $17.5 \%(<10 \mathrm{ng} / \mathrm{ml})$ to $61.5 \%(>200 \mathrm{ng} / \mathrm{ml})$ and the negative prediction value for $\mathrm{sPTB}<30$ weeks at $<10 \mathrm{ng} / \mathrm{ml}$ was $98 \%$. 4/13 (30\%) of women with qfFN > $200 \mathrm{ng} / \mathrm{ml}$ delivered $<30$ weeks gestation. Using combined $\mathrm{CL} / \mathrm{qfFN}$ testing, the positive prediction value of a qfFN value $>200 \mathrm{ng} / \mathrm{ml}$ and $\mathrm{CL}<25 \mathrm{~mm}$ was $87.5 \%$ for SPTB $<37$ weeks.

Conclusion This is the first report of $10 \mathrm{qfFN}$ in twins, demonstrating that it adds predictive value to the qualitative results (negative cut-off at $50 \mathrm{ng} / \mathrm{ml}$ ). High levels, even in early pregnancy, are associated with preterm delivery. Using cervical length and qfFN, management can be targeted to this group; e.g. antenatal maternal steroids. Further research should evaluate interventions to prolong pregnancy in this highest risk group, while lower risk women can be reassured.

\section{PF.03 CRITERIA FOR A LEGITIMATE LIFE: TERMINATION OF PREGNANCY FOR NON-LETHAL FETAL ANOMALY AS AN ACCEPTABLE OUTCOME FOR AN AFFECTED PREGNANCY}

doi:10.1136/archdischild-2013-303966.015

$\underline{\mathrm{L} \text { Crowe, }}$ RH Graham, SC Robson, J Rankin. Newcastle University, Newcastle Upon Tyne, UK

Introduction Advances in diagnosis and treatment, coupled with increased social status of people with disabilities, make society's responses to termination of pregnancy for fetal anomaly (TOPFA) more contentious. This study aims to understand medical and social care professionals' perspectives on the meanings and implications of non-lethal disability from birth, and to evaluate the relationship with perceptions of TOPFA.

Methodology Qualitative, in-depth interviews were conducted with 14 medical professionals and 9 social care professionals. The data were analysed using a generative thematic approach.

Results For social care professionals, abnormal experience of life had become the norm; their narratives of the consequences of fetal anomaly for family life were more nuanced, containing more detailed discussion of the complexities of living with a disabled person. In contrast, medical professionals' accounts of family life with an affected person were dominated by the consequences for the affected individual. The impact of predicted long term outcome in relation to decisions about TOPFA varied across both professional groups; at one end of the spectrum, some professional felt perceived risk was enough to support TOPFA; at the other extreme, individuals who had seen positive outcomes with a specific condition felt TOPFA was not acceptable.

Conclusion The professional groups discuss similar issues, but interpret them differently. Social care professionals focused on their professional insight into life with an affected person; this was used as a rationale for both accepting and not accepting TOPFA. Medical professionals focused on the perceived seriousness of the condition and the wording of the legislation.

\section{PF.04 ABNORMAL PLATELET REACTIVITY IN PREGNANCIES COMPLICATED BY INTRAUTERINE GROWTH RESTRICTION}

doi:10.1136/archdischild-2013-303966.016

'S Mullers, ' $\mathrm{N}$ Burke, ${ }^{1} \mathrm{~K}$ Flood, ' ${ }^{1} \mathrm{H}$ O'Connor, 'M Dempsey, ${ }^{2} \mathrm{~B}$ Cotter, ${ }^{1} \mathrm{E}$ Tully, ${ }^{2} \mathrm{P}$ Dicker, ${ }^{1} \mathrm{M}$ Geary, ${ }^{2} \mathrm{D}$ Kenny, 'FD Malone. 'RCSI, Rotunda Hospital, Dublin, Ireland; 'Royal College of Surgeons Ireland (RCSI), Dublin, Ireland

Platelet function in pregnancies complicated by intra-uterine growth restriction (IUGR) is not well understood. We sought to evaluate platelet function in response to multiple concentrations of multiple agonists in pregnancies complicated by IUGR using a novel platelet function assay.

Cases of intrauterine growth restricted singleton pregnancies were recruited following ultrasound diagnosis between 24-40 weeks gestation (estimated fetal weight $<10^{\text {th }}$ centile for gestational age) in a tertiary referral centre. A modification of standard light transmission aggregometry was used to assess platelet reactivity. Several agonists were assessed at incremental concentrations to characterise the response to multiple receptors. The findings were compared to healthy controls matched for gestational age with normal fetal weight.

A total of 24 pregnancies complicated with IUGR and 36 healthy controls were recruited. Platelet reactivity in response to the agonists Arachidonic acid, Adenosine-diphosphate, Epinephrine and Thrombin-receptor activating protein was significantly reduced in the IUGR cohort. There was a nonsignificant trend to decreased reactivity in response to collagen (Table 1 ).

Abstract PF.04 Table 1 Concentration of EC $_{50}$ for each agonist

\begin{tabular}{llll}
\hline Agonist & EC50 & & P value \\
\hline & Normal pregnancy & IUGR & \\
Arachidonic acid & 0.064 & 0.283 & $<0.0001$ \\
Adenosine-diphosphate & 21 & 54 & 0.0007 \\
Collagen & 0.052 & 0.427 & 0.0973 \\
Epinephrine & 231.4 & 3839 & 0.0015 \\
Thrombin-receptor & 10.27 & 71.54 & $<0.0001$ \\
activating protein & & & \\
\hline
\end{tabular}

In pregnancies complicated by IUGR there is a significant decrease in platelet function compared to healthy pregnant controls. This may reveal valuable insights into the patho-physiology of the disease, and may represent an inadequate growth factor response in IUGR. Further evaluation of the role of platelets may and aid in the development of future interventions for IUGR.

\section{PF.05 ADVANCES IN TRISOMY 21 SCREENING IN THE WEST} MIDLANDS, 1995-2011

doi:10.1136/archdischild-2013-303966.017

${ }^{1} \mathrm{AM}$ Tonks, ${ }^{1} \mathrm{AS}$ Gornall, ${ }^{2} \mathrm{SA}$ Larkins, ${ }^{2} \mathrm{~S}$ Hamilton, ${ }^{1} \mathrm{JO}$ Gardosi. ${ }^{1}$ Perinatal Institute, Birmingham, UK; ${ }^{2}$ West Midlands Regional Genetics Laboratory, Birmingham, UK 